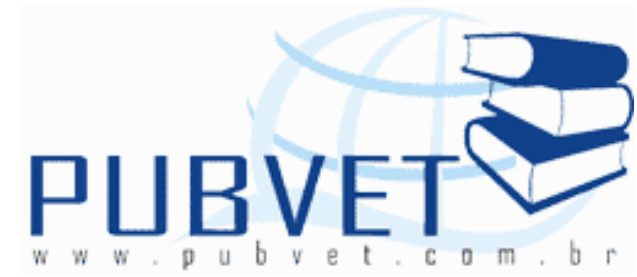

PUBVET, Publicações em Medicina Veterinária e Zootecnia.

\title{
Potencialidade da consorciação de gramíneas e leguminosas forrageiras em pastagens tropicais
}

\footnotetext{
Tiago Adriano Simioni ${ }^{1}$, Fagner Junior Gomes ${ }^{1}$, Ubiara Henrique Gomes Teixeira ${ }^{1}$, Geferson Antonio Fernandes ${ }^{2}$, Leonardo Antonio Botini ${ }^{1}$, Claudio Jonasson Mousquer ${ }^{3}$, Wanderson José Rodrigues de Castro ${ }^{3}$, Alvair Hoffmann ${ }^{1}$

${ }^{1}$ Mestrandos em Zootecnia da UFMT, campus de Sinop-MT, Brasil

2 Zootecnista, UFMT, campus de Sinop-MT

${ }^{3}$ Mestrandos em Ciência Animal da UFMT/FAMEVZ, campus de Cuiabá-MT, Brasil
}

\section{Resumo}

A consorciação é a prática de associar numa mesma área o plantio de culturas diversas para aumentar o rendimento, enriquecer a vida biológica do solo e protegê-lo contra a erosão. Entretanto, o estabelecimento e manejo do consórcio devem ser priorizados, pois as leguminosas e gramíneas forrageiras tropicais apresentam marcantes diferenças morfofisiológicas, sendo necessário um consórcio com resiliência e harmonia para o sucesso do sistema. Dentre os benefícios das leguminosas podemos destacar a fixação biológica de nitrogênio e a transferência para as gramíneas, de forma direta ou indireta, aumento da fertilidade do solo, melhorias na produção animal e redução dos custos de produção. Porém, alguns fatores implicam em limitações para adoção da consorciação, como a disponibilidade de um germoplasma adaptado, fatores 
ecofisiológicos e agronômicos, bem como a falta de conhecimento sobre a técnica e aceitação do sistema. Entretanto, as perspectivas para as próximas décadas, justificam plenamente o investimento em pesquisas visando ampliar a produção de ruminantes em pastagens consorciadas de gramíneas e leguminosas, que se encaixa perfeitamente dentro da filosofia de intensificação da produção pecuária de forma sustentável, tanto nas regiões tropicais quanto nos países de clima temperado.

Palavras-chave: Pecuária, Produção Animal, Zootecnia

\section{Abstract}

Intercropping is the practice of associating in the same area by planting various crops to increase yield, enrich the biological life of the soil and protect against erosion. However, the establishment and management of the consortium should be prioritized, as legumes and tropical grasses exhibit striking morphological and physiological differences, necessitating a consortium with resilience and harmony for the success of the system. Among the benefits of legumes can highlight the biological nitrogen fixation and transfer to grasses, directly or indirectly, increase soil fertility, improvements in animal production and reducing production costs. However, some factors imply limitations to adoption of intercropping, as the availability of adapted germplasm, agronomic and ecophysiological factors, as well as lack of knowledge about the technique and system acceptance. Meanwhile, the outlook for the coming decades, fully justify the investment in research aimed at increasing the production of ruminants in mixed pastures of grasses and legumes, which fits perfectly into the philosophy of intensification of livestock production sustainably, both in the tropics as in temperate countries.

Keywords: livestock, Animal production, Animal Science

\section{INTRODUÇÃO}

A pecuária brasileira é caracterizada pelo sistema extensivo baseada na utilização das pastagens, as quais representam à fonte mais abundante e 
econômica na alimentação de ruminantes. Apesar de o Brasil deter um dos maiores rebanhos bovinos comerciais do mundo, cerca de 209 milhões de cabeça (IBGE, 2011), observa-se que a taxa de lotação média é muito baixa, resultando em produtividade inferior ao potencial do setor pecuário.

Dentre os vários fatores que contribuem para essa baixa produtividade, pode-se destacar a estacionalidade na oferta de alimento como um fator agravante para o setor produtivo. Basicamente, em todas as regiões do Brasil, a estacionalidade é caracterizada por variações na disponibilidade e qualidade da forragem em reposta às alterações nas condições climáticas, as quais não permitem que as plantas forrageiras tenham crescimento uniforme durante 0 ano.

Nesse contexto, a adoção de técnicas que minimizem as perdas de produtividade das pastagens, provenientes de fontes sustentáveis e economicamente viáveis, passa a ser consideras. Uma delas é a consorciação de gramíneas com outras espécies, especialmente leguminosas, que podem diminuir a utilização de adubos nitrogenados, via fixação biológica de nitrogênio, diminuindo os impactos ambientais e melhorando a qualidade da forragem (Assmannet al., 2004).

A introdução de leguminosas em áreas constituídas por gramíneas também pode contribuir para a melhoria da dieta dos animais (Santos et al., 2002), aumento no período de pastejo e no rendimento animal, além de contribuir para recuperação de pastagens com algum grau de degradação (Assmann et al., 2004).

Em regiões onde a maioria da produção pecuária é baseada em pastagens, essa técnica pode auxiliarpara a diversificação das forrageiras na propriedade, com incremento naprodutividade forrageira e no desempenho dos animais, e, por consequência, melhoria na qualidade do solo e redução de eventuais impactos ambientais. Visando, também, eficiente gestão da produção e utilização da forragem produzida. 


\section{NITROgÊNIO NO ECOSSISTEMA DA PASTAGEM}

\subsection{Importância do Nitrogênio ( $N$ )}

O nitrogênio é encontrado na natureza na forma gasosa $\left(\mathrm{N}_{2}\right)$, formando cerca de $78 \%$ do ar atmosférico. Também encontrado na forma iônica $\left(\mathrm{NH}_{4}{ }^{+}\right.$, $\mathrm{NO}_{2}{ }^{-}$e $\mathrm{NO}_{3}{ }^{-}$) e ainda, em diversas estruturas orgânicas como aminoácidos (unidades fundamentais das proteínas) e nucleotídeos, com subunidades formadoras do RNA, DNA e adenosina trifosfato (ATP), além de diversos outros compostos orgânicos (Monteiro, 1998).

Além de ser constituinte dos aminoácidos livres e proteicos, o nitrogênio está presente em outros compostos nitrogenados importantes, como as bases nitrogenadas (purinas e pirimidinas) e os ácidos nucleicos que perfazem cerca de $10 \%$ do total do nitrogênio na planta. Outras formas amino solúveis chegam a compor $5 \%$ do $\mathrm{N}$ das plantas. A fração presente como $\mathrm{NH}^{-3} \mathrm{e}$ $\mathrm{NH}^{+4}$ geralmente representa baixa porcentagem (Conn\&Stumpf, 1975; Mengel \&Kirkby, 1987).

Nas folhas o nitrogênio está nos cloroplastos como constituinte da molécula de clorofila (Figura 2), onde cada átomo de Mg está ligado a quatro átomos de nitrogênio e também participa da síntese de vitaminas, hormônios, coezima, alcalóides, hexosaminas e outros compostos (Taiz\&Zeiger, 2006).

O nitrogênio é um nutriente que está relacionado aos mais importantes processos fisiológicos que ocorrem nas plantas, tais como fotossíntese, respiração desenvolvimento e atividade das raízes, absorção iônica de outros nutrientes, perfilhamento, diferenciação celular e genética (Taiz\&Zeiger, 2006).

De modo geral, o nitrogênio é o principal nutriente das gramíneas, proporcionando aumento imediato da produção de forragem. Solos deficientes em nitrogênio acarretam em crescimento lento, porte baixo, plantas com poucos perfilhos e o teor de proteína bruta tornam-se insuficiente à alimentação animal (Van Raij, 1991). 


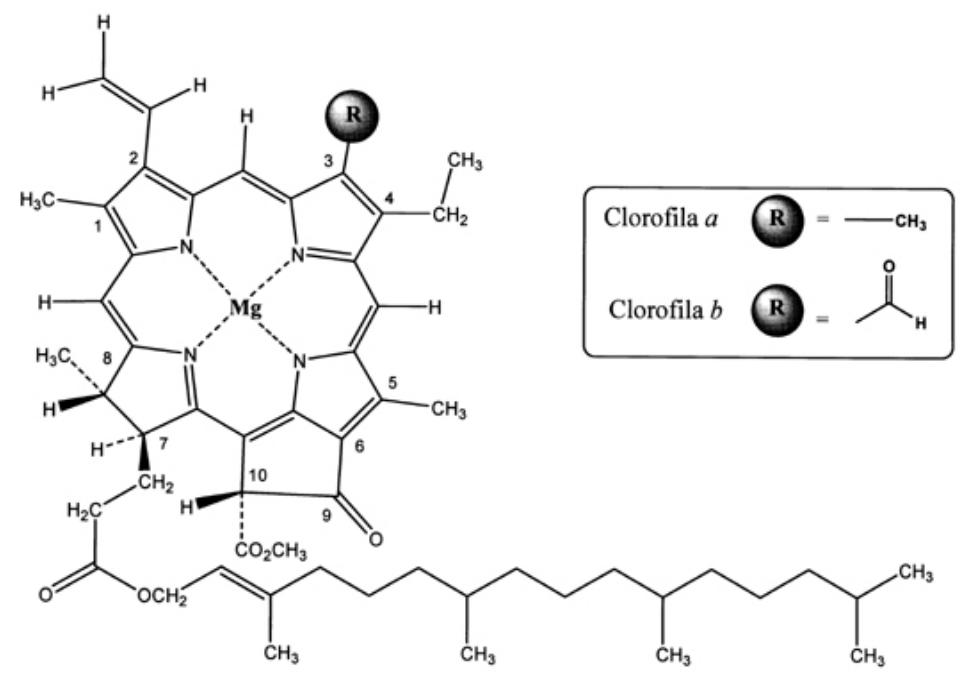

Figura 2 - Estrutura química da clorofila $a$ e clorofila $b$. Fonte: Streitet al., 2005.

\subsection{Ciclo do Nitrogênio}

A principal forma de transformação de $\mathrm{N}$ atmosférico para a forma assimilável É pelo ciclo bioquímico do nitrogênio (Figura 3), onde através da captura do $\mathrm{N}$ atmosférico as bactérias convertem, por inúmeras reações, uma forma assimilável de $\mathrm{N}$ para que todos os organismos possam utilizá-los.

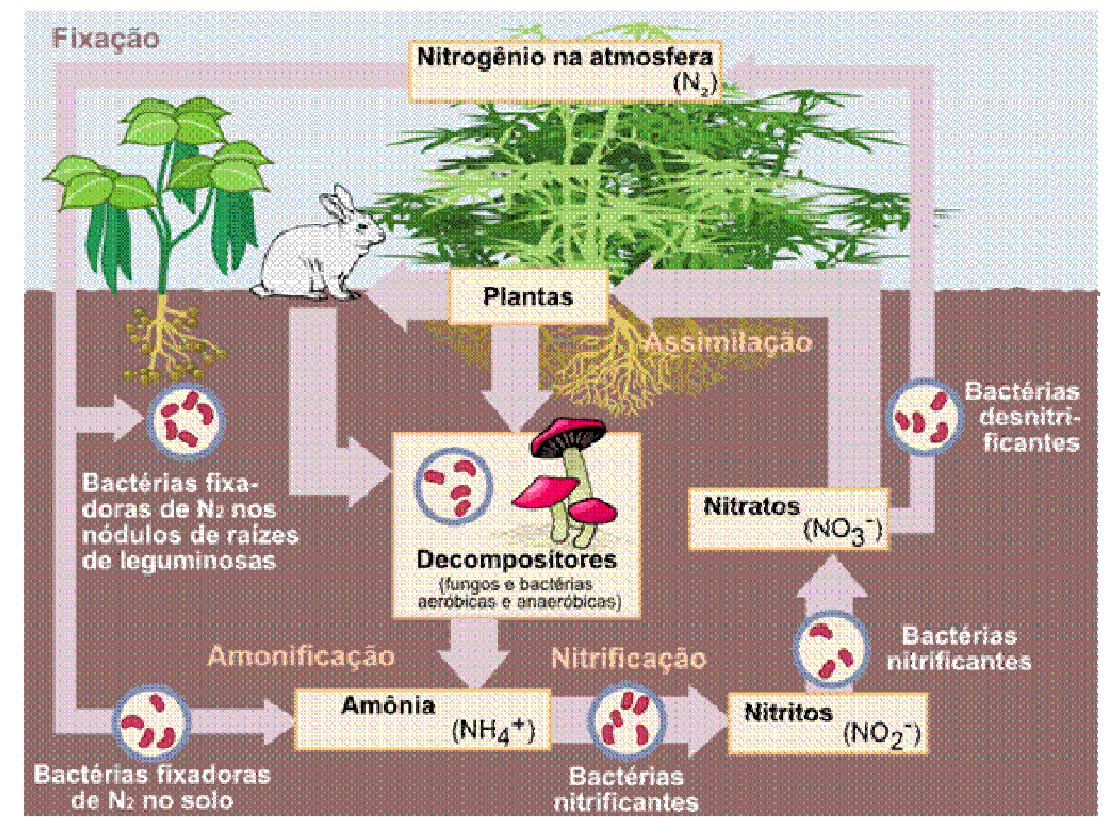

Figura 3 - Ciclo do nitrogênio. Fonte: Gallo\& Basso, 2012. 
Grande parte do nitrogênio encontrado no solo provém de materiais orgânicos mortos, nos quais existe sob a forma de compostos orgânicos complexos, tais como proteínas, aminoácidos, ácidos nucleicos e nucleótides. Entretanto, estes compostos nitrogenados são, em geral, rapidamente decompostos em substâncias mais simples por organismos que vivem nos solos. As bactérias saprófitas e várias espécies de fungos são os principais responsáveis pela decomposição de materiais orgânicos mortos. Estes microrganismos utilizam as proteínas e os aminoácidos como fonte para suas próprias proteínas e liberam o excesso de nitrogênio sob a forma de amônio $\left(\mathrm{NH}_{4}+\right)$. Este processo é denominado amonificação. $O$ nitrogênio pode ser fornecido sob a forma de gás amoníaco $\left(\mathrm{NH}_{3}\right)$, mas este processo ocorre geralmente apenas durante a decomposição de grandes quantidades de materiais ricos em nitrogênio, como numa grande porção de adubo ou fertilizante. Em geral, a amônia produzida por amonificação é dissolvida na água do solo, onde se combina a prótons para formar o íon amônio (Moreira et al. 2002)..

Após, ocorre a fase denominada nitrificação, onde ocorre a oxidação do amoníaco, com produção de energia, que é utilizadapor bactérias, denominadas autotróficas quimiossintéticas, para reduzir o dióxido de carbono. Esse processo é dividido em duas fases, uma ocorre com a atuação de bactérias Nitrosomonas que convertem $\mathrm{NH}_{3}$ em nitrito $\left(\mathrm{NO}_{2}\right): 2 \mathrm{NH}_{3}+3 \mathrm{O}_{2} 2$ $\mathrm{NO}_{2}+2 \mathrm{H}++2 \mathrm{H}_{2} \mathrm{O}$. O nitrito é tóxico para as plantas superiores, mas raramente se acumula no solo. A outra é a conversão do $\mathrm{NO}_{2}$ em nitrato $\left(\mathrm{NO}_{3}\right)$, pelas bactérias Nitrobacter, que é a forma sob a qual quase todo o nitrogênio se move do solo para o interior das raízes, através da conversão de $2 \mathrm{NO}_{2}+\mathrm{O}_{2}$ $2 \mathrm{NO}_{3}$,ambas presentes no solo e de suma importância para a fixação biológica de nitrogênio (Moreira et al. 2002).

Com $0 \mathrm{NO}_{3}$ formado, pode então ser lixiviado, porém essa condição em solos tropicais é pouco provável, já que, os solos são pobres desse nutriente e as raízes das plantas captam rapidamente essa forma de nitrogênio, utilizando de forma eficiente para seu metabolismo (Moreira et al. 2002). 
Essa forma de nitrogênio pode também ser desnitrificada, por meio de microorganismos, que em anaerobiose, utilizam o oxigênio da ligação para respiração própria, liberando $\mathrm{N}$, que volta para a atmosfera (Moreira et al. 2002).

O ciclo do nitrogênio é a forma essencial de fixação, com $75 \%$ de eficiência em relação aos outros métodos, como por exemplo, a fixação industrial de nitrogênio (Haber-Bosch), porém, esse processo requer altas quantidades energéticas, aproximadamente $400^{\circ}$ a $600^{\circ} \mathrm{C}$, e com pressão controlada de 100 a 200 amt., para que possa fixar pequenas quantidades, não ultrapassando os $15 \%$, não sendo viável para determinada sistemas de produção (Raven et al., 1996).

\subsection{Fixação Biológica de Nitrogênio (FBN)}

O nitrogênio atmosférico pode ser utilizado apenas por algumas bactérias com capacidade enzimática para fazer sua redução, através do processo de fixação biológica de nitrogênio (Monteiro, 1998).

A fixação biológica de nitrogênio se dá com a participação de um complexo enzimático (Figura 3) denominado nitrogenase e com a participação de Fe, Mg, Mo e ATP (Monteiro, 1998), que converte o $\mathrm{N}$ atmosférico para a forma assimilável pelas plantas, utilizando a ferredoxina como transportadora de elétrons, pois é necessário que 8 hidrogênios sejam utilizados para unir-se ao $\mathrm{N}$ e transformá-lo em $\mathrm{NH}_{3}$, (Raven et al., 1996).

Por ser o resultado de complexas reações fisiológicas e bioquímicas, muitas vezes envolvendo espécies distintas, a fixação biológica de $\mathrm{N}_{2}$ depende da expressão do potencial genético do microrganismo, do hospedeiro ou de ambos, no caso de sistemas simbióticos (Miller \&Heichel, 1995).

Segundo Carvalho (1986) várias leguminosas possuem a capacidade de se unir com diversas espécies de bactérias fixadoras de nitrogênio, uma união simbiótica que gera benefícios para ambos os organismos. A bactéria usa a energia do metabolismo fotossintético da leguminosa, e esta, se beneficia do 
nitrogênio fixado para aumentar o seu desempenho produtivo, onde muitas vezes é limitado pela falta desse nutriente.

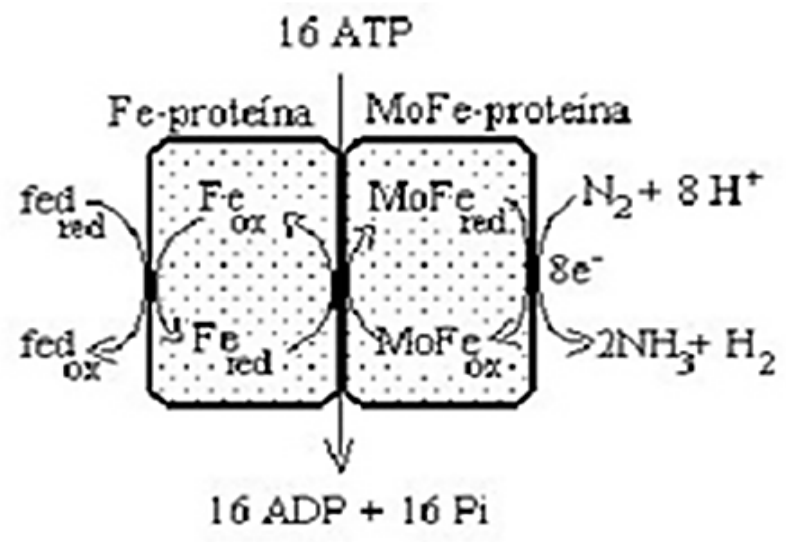

Figura 4-Complexo enzimático de fixação do nitrogênio atmosférico. Fonte: Ravenet al., 1996.

Além da absorção na forma de nitrogênio assimilado, outros nutrientes são necessários para a manutenção da leguminosa, como absorção de nitrato e amônio ( $\mathrm{N}$ mineral) do solo, que são utilizados para atingir o máximo de absorção de N e aumentar crescimento das plantas (Vallis, 1978).

Existem inúmeras espécies que fixam nitrogênio na forma biológica, entre elas estão asespécies de Rhizobium, Bradyrhizobium e até Azospirillum, que possuem forma de fixação pela simbiose ou até que fixam por meio de vida livre, ou seja, não necessitem da formação de nódulos para a sobrevivência (Döbereiner, 1997).

Após essas bactérias fazerem a fixação do nitrogênio, ocorre à síntese de novos produtos através desse nutriente, dentro do nódulo ou bacterióide, a forma $\mathrm{NH}_{3}$ entra em contato com o substrato aquoso do citoplasma e é convertida, rapidamente, em $\mathrm{NH}_{4}$ (Figura 5). Porém, essa forma inibe a fixação se forem mantidas dentro do nódulo, logo, enzimas agem para converter essa forma de nitrogênio em produtos que serão utilizados no metabolismo da bactéria ou da planta (Tonin, 1988). 
A ação das enzimas GS (glutamina sintetase) e GOGAT (glutamato sintase) são essências para viabilizar o nitrogênio $\left(\mathrm{NH}_{4}\right)$ em produtos que serão a principal forma de reserva de energia para o metabolismo da planta, os aminoácidos (Tonin, 1988). As enzimas participantes convertem o $\mathrm{NH}_{4}$ em principais aminoácidos que serão base para os demais metabolismos, a glutamina e o glutamato são os principais aminoácidos formados, que irão dar origem a novos compostos, como asparagina e ureídeos, formas de transporte de nitrogênio para o restante da planta, seja de clima temperado ou tropical (Taiz\&Zeiger, 2006).

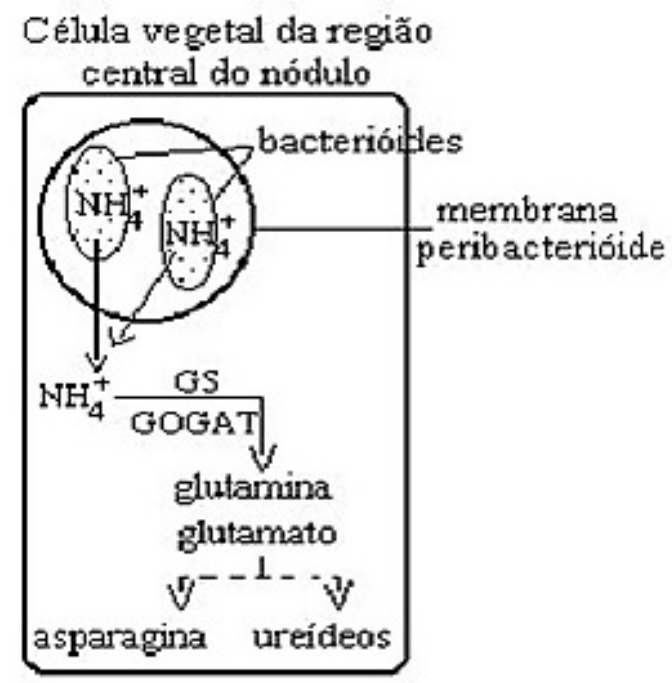

Figura 5 - Conversão de produtos assimiláveis pelas plantas, na célula vegetal da região central do nódulo. Fonte: Tonin, 1988.

Para a maioria das plantas que não realizam associação com organismos fixadores, estes, absorvem o nitrogênio do solo sob a forma de nitrato $\left(\mathrm{NO}_{3}\right)$ que passa por um processo de redução que culmina na formação de $\mathrm{NH}_{4}$. Inicialmente, $\mathrm{O} \mathrm{NO}_{3}$ é reduzido a nitrito $\left(\mathrm{NO}_{2}\right)$ pela ação do nitrato redutase e, em seguida, esse é reduzido a $\mathrm{NH}_{4}$ pela ação da nitritoredutase. Uma vez produzido o $\mathrm{NH}_{4}$, este será assimilado pelas enzimas GS e GOGAT, como visto anteriormente (Taiz\&Zeiger, 2006).

Algumas práticas comumente utilizadas podem comprometer a fixação biológica de nitrogênio, como aplicação de altas quantidades de $\mathrm{N}$ mineral, pois 
a disponibilização de fertilizantes no sistema inibe a formação de novos nódulos, gerados pela simbiose com as bactérias e substitui parcialmente a fixação simbiótica, usando apenas o $\mathrm{N}$ mineral como a fonte para leguminosas (Allos\& Bartholomew, 1959).

\section{QUANTIDADE DE NITROGÊNIO FIXADO E SUA TRANSFERÊNCIA PARA AS GRAMÍNEAS}

O uso de leguminosas em pastagens é uma alternativa para obter manejo sustentável de solo e água, potencialmente atribuindo para algumas vantagens, como incremento a fertilidade do solo, com a fixação biológica do nitrogênio; aumenta a eficiência de reciclagem de nutrientes, com acumulo de biomassa que beneficia a pastagem, dentre outros fatores que possam ser benéfico ao sistema (Lal, 1991).

Segundo Andrade (2010) a quantidade de nitrogênio fixada anualmente por meio da simbiose de leguminosas com rizóbios é de, aproximadamente, 70 milhões de toneladas. Assumindo que pelo mens $70 \%$ desta quantidade é utilizada na agricultura e em sistemas agroflorestais, em substituição aos fertilizantes nitrogenados comerciais, ao redor de 50 milhões de toneladas de nitrogênio fixado seriam disponibilizados para a produção agrícola (Werner \& Newton, 2005), gerando uma economia estimada em 10 bilhões de dólares anualmente (Howiesonet al., 2008).

De acordo com Giller (2001), o potencial de FBN das leguminosas forrageiras tropicais é superior a $300 \mathrm{~kg} / \mathrm{ha} / \mathrm{ano}$, sendo que a maioria dos resultados obtidos situa-se na faixa de até $180 \mathrm{~kg} / \mathrm{ha} / \mathrm{ano}$ de $\mathrm{N}$ (Miranda et al., 2003). Em estudos na região dos cerrados, Cadischet al. (1994) relataram estimativa de FBN de 84 kg/ha/ano para consórcio entre Brachiaria decumbens com Calopogonium mucunoides.

A contribuição prática da FBN pode ser mensurada pelos números decorrentes do uso de inoculantes de rizóbio em diversas culturas, substituindo 
total ou parcialmenteos fertilizantes nitrogenados e propiciando uma economia significativa nos custos deprodução (Tabela 1).

Tabela 1 - Exemplos de algumas leguminosas nodulíferas com respectivas taxas de fixação biológica de $\mathrm{N}$.

\begin{tabular}{cc}
\hline Leguminosas & $\mathbf{k g} / \mathbf{h a / a n o}$ \\
\hline Alfafa (Medicago sativa) & $127-333$ \\
Calopogonio (Calopogoniummucunoides) & $64-450$ \\
Amendoim (Arachishypogaea) & $33-297$ \\
Caupi (Vignaunguiculata) & $73-240$ \\
Crotalária (Crotalariajuncea) & $197-249$ \\
Estilosantes (Stylosanthessp.) & $20-263$ \\
Guandu (Cajanuscajans) & $7-235$ \\
Leucena (Leucaenaleucocephala) & $400-900$ \\
Soja (Glycine Max) & $17-450$
\end{tabular}

Fonte: Moreira \& Siqueira (2006) citando por Calegariet al. (1993); Hardarson (1993); Peoples et al. (1995).

Além de tudo, as leguminosas associadas às gramíneas, em pastagens consorciadas, formam um complexo que beneficia a produtividade animal, como efeito direito. De forma indireta, seriam obtidos resultados nas culturas que sucedem as áreas de pastagens, beneficiando a relação $\mathrm{C}: \mathrm{N}$ do solo, possibilitando aumento da taxa de mineralização da matéria orgânica (Peixoto et al. 2001).

Portanto, os estudos demonstram claramente que é possível aumentar a longevidade das pastagens cultivadas em regiões tropicais por meio da utilização de consórcio com leguminosas forrageiras produtivas e persistentes. Para isso, as leguminosas devem constituir de 20 a $45 \%$ da composição botânica das pastagens tropicais para que os níveis de FBN obtidos de, aproximadamente 60 a $120 \mathrm{~kg} / \mathrm{há} / \mathrm{ano}$, sejam suficientes para manter o balanço de $\mathrm{N}$ no solo (Cadischet al., 1994). 


\subsection{Vias de Transferência}

Existem algumas vias principais para transferência do $\mathrm{N}_{2}$ fixado simbioticamente pelas leguminosas, que podem ser vias de transferência direta e indireta, que se diferencia apenas pelas formas ou meios de como o $\mathrm{N}$ fixado passa a ser absorvido.

\subsubsection{Via Direta}

Em estudos com leguminosas e gramíneas, Gebhart, etal. (1993) sugerem que há transferência direta do $\mathrm{N}$ da leguminosa para a gramínea por mecanismos que atuam em curto prazo e a pequenas distâncias.

Componentes solúveis de $\mathrm{N}$, de baixo peso molecular, como aminoácidos ou amônio, de raízes e nódulos de leguminosas são liberados no solo ou atmosfera, e capturados por raízes ou folhas de gramíneas vizinhas (Taet al., 1986, citado por Cantarutti et al., 1997), mas tal liberação responde somente por pequenas proporções do $\mathrm{N}$ total fixado.

Outra via de transferência de $\mathrm{N}$ em curto prazo ou transferência direta de $\mathrm{N}$ inclui hifas de micorrizas, que são conexões entre as raízes de leguminosas e gramíneas (Haysteadet al., 1988, citado por Cantarutti et al., 1997); e também, a reabsorção do $\mathrm{N}$ volatilizado (amônia) ou lixiviado (nitrato) das folhas de leguminosas, pelas folhas de gramíneas (Denmead et al., 1976).

Esses meios de transferência de $\mathrm{N}$ fixado não são muito relevantes em comparação aos outros métodos, pois as pesquisas nesses sentidos não comprovam que é a principal via de transferência ou de absorção pelas outras espécies em contato com as leguminosas.

\subsubsection{Via Indireta}

Uma proporção significativa do $\mathrm{N}$ fixado pela leguminosa é transferido e absorvido indiretamente por mecanismos de reciclagem que ocorrem subterraneamente, através da senescência de raízes e nódulos.Até mesmo de maneira superficial, onde o consumo do $\mathrm{N}$ de leguminosas pelos animais em 
pastejo e excreção desse $\mathrm{N}$ através de fezes e urina e subsequente absorção de $\mathrm{N}$ mineral pela gramínea associada.

O N presente nas fezes e, principalmente, na urina estão em formas mais prontamente disponíveis contribuindo para evidenciar a importância na reciclagem e na transferência de N. No entanto, a contribuição relativa das excreções animais para a transferência do $\mathrm{N}$ é dependente de uma alta porcentagem de utilização das leguminosas, da quantidade de excreções, da área coberta por essas excreções e da uniformidade de distribuição da excreta (Vallis, 1978, citado por Cantaruttiet al., 1997). Já que, o que normalmente é observado, é a concentração de muita excreta em áreas não produtivas e a deposição localizada não permite alta absorção de $\mathrm{N}$ pelas gramíneas (Cantaruttiet al., 1997).

Entretanto, o controle do pastejo pode promover uma maior uniformidade de deposição de excreta que, teoricamente, poderia melhorar a eficiência de transferência de $\mathrm{N}$ através dos animais. Porém, a alta volatilidade de $\mathrm{N}$ da urina limita o grau com o qual o manejo do pastejo pode ser usado para melhorar a eficiência de transferência de $\mathrm{N}$. Modelos têm sido propostos para demonstrar a importância da reciclagem de $\mathrm{N}$ através dos resíduos vegetais (Cadishet al., 1994; Cantarutti, 1997).

A liberação de nitrogênio pela decomposição de material de leguminosas no solo com liberação microbiana de nitrato e amônio, tem se mostrado a via mais importante para transferência de $\mathrm{N}$, segundo Cantaruttiet al., 1997, comparado com a absorção de componentes solúveis de $\mathrm{N}$, liberados recentemente para as gramíneas, ou do $\mathrm{N}$ de excreto animal.

A transferência através da decomposição de leguminosas envolve um período importante entre a senescência dos tecidos de leguminosas e absorção de $\mathrm{N}$ através de plantas de gramíneas associadas devido a uma cadeia de transformações e residência microbianas em vários pontos da biomassa microbiana e matéria orgânica morta (Cadischet al., 1994). 


\section{CARACTERÍSTICAS DE ALGUMAS LEGUMINOSAS}

\subsection{Gênero Stylosanthes}

Segundo Silva\&Zimmer(2004)， o gênero Stylosanthes possui 44 espécies, sendo que 25 ocorrem no Brasil, principalmente na região do Cerrado. Possui o maior número de cultivares dentre as leguminosas tropicais usadas como pastagens. No Brasil oito cultivares foram liberados comercialmente no mercado. As espécies $S$. guianensis, $S$. capitata e $S$. macrocephala são as principais espécies com potencial de uso no Brasil. Atualmente encontra-se no mercado dois cultivares deste gênero, o estilosantes Mineirão e o Campo Grande.

$\mathrm{O}$ estilosante Mineirão é perene, semiereto, podendo atingir $2,5 \mathrm{~m}$ de altura. É muito tolerante à antracnose e permanece verde durante o período seco, possuindo boa adaptação e desempenho desde Roraima até São Paulo e Mato Grosso do Sul (Silva\&Zimmer, 2004). É recomendado para ser utilizado em pastagens consorciadas, banco de proteína, recuperação de pastagens ou em associação com culturas anuais como adubo verde.

O cultivar Campo Grande foi desenvolvido pela Embrapa Gado de Corte, com uma mistura física de sementes com $80 \%$ (em peso) de linhagens de $S$. capitata, tolerantes à antracnose, e $20 \%$ de linhagens de S. macrocephala. Este cultivar tem apresentado bom desempenho em solos com textura arenosa e média. É utilizado em consórcio, com grande potencial na utilização em recuperação de pastagens e de áreas degradadas.

Os Stylosanthes, em geral, são tolerantes a solos ácidos e com baixa fertilidade, aumentando a produtividade com o uso de fertilizantes, compropagação através de sementes. Esses gêneros são bastante usados em consórcio, com atributos ao ganho ou manutenção do peso de animais durante o período de seca, como resultado da melhor qualidade da leguminosa, sendo o principal benefício da pastagem consorciada sobre pastagem pura de gramínea (Peixoto et al. 2001). 
As características desses gêneros proporcionam uma compatibilidade e grande influência na permanência na pastagem, possuindo grande capacidade de ressemeadura natural, grande sobrevivência e persistência na área, podendo também ser usados como banco de proteína em alguns casos (Peixoto et al. 2001).

\subsection{Gênero Arachis}

O gênero Arachis é composto por espécies diplóides $(2 n=2 x=20$; ou, $2 x=18)$ e tetraplóides $(2 n=4 x=40)$ (Fernández\&Krapovickas, 1994). Ocorre naturalmente na América do Sul, estendendo-se ao leste dos Andes, sul da Amazônia, norte da Planície Platina e noroeste da Argentina (Krapovickas\& Gregory, 1994). Existem aproximadamente 80 espécies neste gênero, 64 destas ocorrem no Brasil, sendo 48 restritas ao território brasileiro. Quinze estão distribuídas na Bolívia, 14 no Paraguai, 6 na Argentina e 2 no Uruguai (Valls\& Simpson, 1994).

Seu hábito de crescimento e ciclo de vida perene tem despertado grande interesse em âmbito nacional e internacional para consorciação com gramíneas, apresentando boa produção de forragem, com grande capacidade de fixar nitrogênio e também boa tolerância ao sombreamento (Peixoto et al. 2001).

As principais restrições apresentadas a espécies forrageiras deArachis baseiam-se principalmente no seu alto custo de implantação e no seu lento estabelecimento (Kerridge, 1994). O custo de produção de sementes é elevado, principalmente devido a frutificação geocarpia da espécie, com 90\% da produção de frutos ocorrendo a uma profundidade de até $10 \mathrm{~cm}$ no solo (Fergusonet al., 1992; Carvalho, 1996), o que impõe a necessidade de busca por acessos com alta produção de sementes, e, ou, com sua formação mais superficial.

Segundo Valle (2001), as espécies de Arachis revitalizaram o interesse em leguminosas tropicais devido ao seu valor como forrageira e densa 
cobertura do solo, sendo chamadas de "alfafa das savanas" em função de seu valor nutritivo e palatabilidade. Praticamente todas as espécies de Arachis produzem forragem de boa qualidade e em razoável quantidade, quando comparadas com espécies de outros gêneros de leguminosas utilizadas comercialmente (Valls\& Simpson, 1994).

A grande vantagem do uso desse gênero em consórcio é pelo seu hábito de crescimento, que é parecido com os da gramínea, favorecendo a persistência e durabilidade do consórcio, sem sofrer grandes prejuízos com o crescimento agressivo da gramínea (Peixoto et al. 2001).

\subsection{Gênero Leucaena}

O gênero Leucaena compreende árvores fixadoras de nitrogênio, nativas das Américas e distribuídas desde o sul do Texas até o Perú. Segundo Schifino-Wittmann (2004) esse gênero possui múltiplas utilizações, que incluem a produção de madeira, alimentação humana, forragem para o gado, adubação verde, sistemas agroflorestais, artesanato, cercas e cercas vivas, etc.

Possui inúmeras espécies sendo usadas em vários sistemas agrícolas. A mais utilizada na alimentação animal em todo mundo é a espécie Leucaenaleucocephala. A importância econômica dessa espécie se deve ao seu valor como árvore de sombreamento e adubo verde, além do interesse na sua utilização nos trópicos para restauração da fertilidade do solo, forragem e recuperação de áreas degradadas (Freitas et al., 1991), uma vez que ela se desenvolve bem em encostas íngremes, solos marginais e regiões com períodos de seca (Perez \&Fanti, 1999).

Segundo informações da Embrapa Gado de Corte, plantas do gênero Leucaena devem ser implantadas preferentemente em área de boa fertilidade, ou mesmo em local que tenha sido corrigido e adubado e que possa ser irrigado. Como é uma planta perene, é necessário considerar que a área plantada permanecerá imobilizada por muitos anos. A proporção dessa espécie 
na propriedade leva em consideração a categoria animal atendida, o número de animais e de dias que será fornecida.

No uso em consorciação acarreta alguns problemas, não suportando grande intensidade de pastejo, sendo utilizadas como banco de proteína, com alta contribuição para a dieta animal, bem como suplemento alimentar para o período da seca, com alta produção de folhas e matéria seca (SchifinoWittmann, 2004).

Entretanto, segundo avaliação de Schifino-Wittmann (2004), a utilização como alimento exclusivo deve ser avaliada, podendo apresentar efeito adverso à saúde dos animais, por apresentar em sua composição um aminoácido, com efeitoantinutricional, denominado mimosina. Esse componente causa disfunções metabólicas com perda de pelos na cauda, salivação, perda de peso e problemas reprodutivos em vacas. Esses efeitos são observados quando o consumo é superior a $50 \%$ da dieta, por longo período de tempo.

\section{CONSORCIAÇÃO DE GRAMÍNEAS E LEGUMINOSAS}

Segundo Peixoto et al. (2001) a consorciação é a prática de associar numa mesma área o plantio de culturas diversas para aumentar o rendimento, enriquecer a vida biológica do solo e protegê-lo contra a erosão. Considerada como uma técnica agrícola de conservação que visa um melhor aproveitamento em longo prazo do solo, bem como o cultivo na qual se utiliza mais de uma espécie de planta na mesma área e no mesmo período de tempo.

A principal expectativa do uso de leguminosa em pastagens, segundo Pereira (2001), é a melhoria da produção animal em relação à pastagem de gramínea exclusiva, como efeito da participação direta da leguminosa melhorando e diversificando a dieta do animal e também do aumento da disponibilidade de forragem pelo aporte de nitrogênio ao sistema, através da sua reciclagem e transferência para a gramínea acompanhante. 
O correto desempenho do papel das leguminosas em relação à fixação biológica de nitrogênio, acúmulo de biomassa vegetal e ciclagem de nutrientes, preconizam a adoção e o conhecimento de alguns procedimentos corretos referentes ao uso em pastagens consorciadas, para que a adoção de métodos de consorciação seja seguido e não ocorra nenhum colapso do sistema.

\subsection{Estabelecimento e Manejo do Consórcio}

Primeiramente, as leguminosas e gramíneas forrageiras tropicais apresentam marcantes diferenças morfofisiológicas, que, de acordo com Nascimento Jr., et al. (2002), as gramíneas são mais eficientes na utilização de água, de alguns nutrientes minerais e apresentam uma eficiência fotossintética mais alta, que resulta na taxa de crescimento e potencial de produção de forragem superior ao das leguminosas.

O sistema radicular das gramíneas é mais extenso e difuso. As gramíneas têm diversas unidades de crescimento denominadas perfilhos, que são autônomos em relação ao crescimento e dotados de tecidos meristemáticos (gemas) bem localizados. Por outro lado, as leguminosas têm pontos de crescimentos mais expostos em ramificações, geralmente dependentes da planta mãe e em número menor (Nascimento Jr., et al., 2002).

Considerando as vantagens competitivas das gramíneas em relação às leguminosas, o estabelecimento do consórcio deve ser direcionado para favorecer as leguminosas, com redução de 30 a 40 \% das gramíneas da área (Zimmer, 1994). Sem comprometer a produtividade das gramíneas, escolhendo uma associação compatível entre a gramínea e leguminosa, onde as condições climáticas não sejam limitantes, assegurando um suprimento adequado de nutrientes, para otimizar o crescimento da leguminosa forrageira.

O manejo em pastagem consorciada é diferenciado dos demais, pois em uma mesma área existe o cultivo de plantas diferentes, que necessitam de planejamento e domínio de tecnologia, priorizando a resiliência do consórcio 
(Tabela 2), visando a perpetuação da leguminosa no sistema, sem comprometer a gramínea, para que os resultados venham a respondem os esforços de implantação e manutenção do consórcio.

Tabela 2 - Grau de compatibilidade entre gramíneas e leguminosas em pastos consorciados, com base na harmonia e resiliência.

\begin{tabular}{c|cc}
\hline Resiliência & Baixa & Alta \\
\hline Blta & $\begin{array}{c}\text { Incompatível } \\
\text { Instável }\end{array}$ & $\begin{array}{c}\text { Persistente } \\
\text { Compatibilidade Perfeita }\end{array}$ \\
\hline
\end{tabular}

Fonte: Andrade, 2010.

O manejo do pastejo é essencial para garantir a persistência do sistema, onde a entrada e saída dos animais possibilitam que, tanto gramínea como leguminosa, revigorem e possam crescer sem interferência dos animais. A taxa de lotação também deve ser controlada, já que a consorciação não suporta intensas quantidades de animais, nem em sistemas intensivos de explorações, pois a pressão na pastagem é muito intensa não dando tempo para o rebrote.

As leguminosas tropicais são mais sensíveis que as gramíneas a aumentos na pressão de pastejo, este fato tem contribuído para formar um consenso entre pesquisadores de que pastagens consorciadas são mais recomendadas para uso extensivo e que sob regime de pressões de pastejo mais altas, as leguminosas tenderão a desaparecer (Pereira, 2002).

Ainda segundo Pereira (2202), algumas leguminosas persistem menos sob pressões de pastejo extremas, não se deve perder de vista que a pressão de pastejo ideal é a que mantêm a leguminosa na pastagem, possibilitando ao animal colher uma dieta com qualidade e em quantidade suficiente para exteriorizar o seu potencial produtivo. 
O conceito de resistência ao pastejo de algumas leguminosas foi bem detalhado por Briske (1996), que subdividiu esses fatores em mecanismos de escape e de tolerância ao pastejo. Os mecanismos de escape são aqueles que reduzem a probabilidade e a severidade do pastejo, ao passo que a tolerância ao pastejo consiste dos mecanismos que promovem a retomada do crescimento das plantas após a desfolha, tais como disponibilidade de meristema e processos fisiológicos.

Além de estratégias de manejo, a taxa de lotação deve ser avaliada, devido a persistência da leguminosa, dependem também da seletividade exercida sobre ela pelo animal, onde experimentos mostram que determinadas espécies não suportam taxa de lotação acima de 2 novilhos/ha, nem em sistemas rotacionados, onde a leguminosa não consegue persistir por mais de 3 anos na pastagem (Pereira, 2002).

De acordo com Peres (1988) a palatabilidade da leguminosa em pastagens consorciadas é um questão a ser consultada. Segundo o autor, na fase de maior crescimento das pastagens a leguminosa não deve ser muito palatável em relação à gramínea, pois é nesta fase que a gramínea tem o máximo desenvolvimento, assegurando a leguminosa à capacidade de competição, sem correr o risco de serem eliminadas com o passar do tempo, pela alta frequência de desfolha e menor capacidade de competir com as gramíneas.

Uma alternativa, segundo Cadishet al. (1994), é incluir o uso de leguminosas menos palatáveis como uma das opções de manejo para aumentar a fixação de $\mathrm{N}$ no sistema gramínea/leguminosa, apenas visando a fixação biológica de nitrogênio, sem necessariamente, objetivar respostas ao desempenho animal.

\section{BENEFÍCIOS DO USO DE LEGUMINOSAS}

Em vista das características das leguminosas apresentadas anteriormente, para quantificar os benefícios que cada uma dessas pode 
influenciar no consórcio com gramíneas, é necessário avaliar qual se adapta ao sistema, com intuito de desenvolver melhorias na produção animal e vegetal.

Dentre os benefícios do uso de leguminosas a Embrapa Cerrado (2009), identifica alguns dos mais consideráveis, como a melhor qualidade do pasto; maior ganho de peso animal; economia nos gastos com adubação nitrogenada;recuperação de áreas degradadas; maior cobertura de solo e melhor proteção, além da garantia de um processo não poluente e ambientalmente correto. Não se trata de nenhuma novidade, embora o emprego desta técnica, anteriormente, tenha implicado em limitações até pela própria falta de tradição e conhecimento dos pecuaristas e técnicos em usar e manejar adequadamente as pastagens consorciadas.

\subsection{Aumento da Fertilidade do Solo}

Os solos tropicais são caracterizados por seu alto grau de intemperismo, baixa fertilidade natural e alta capacidade de fixação de fósforo. Para torná-los sustentáveis a produção agropecuária é necessário interferência do homem com aporte de insumos externos (Paulino et al., 2000).

A manutenção da produtividade dos sistemas agropecuários tropicais prescreve a importância de recursos renováveis, especialmente a matéria orgânica do solo (Swift et al., 1993), ela representa pelo menos 50\% da capacidade de troca de cátions (CTC) dos solos tropicais, constituindo-se a principal fonte de nutrientes do sistema (Raij, 1987).

Os teores médios de matéria orgânica de solos sob pastagens aumentam com o tempo, porém os teores de $\mathrm{N}$ disponível são insuficientes para manutenção da produtividade, especialmente em pastagens exclusivas de gramíneas (Humphreys, 1994). Este fato é decorrente da baixa taxa de decomposição de gramíneas tropicais, em função da alta relação $\mathrm{C}: \mathrm{N}$, que implica em baixas taxas de mineralização líquida de $\mathrm{N}$ e baixos conteúdos de $\mathrm{N}$ inorgânico no solo, que favorece a degradação das pastagens (Thomas, 1993). 
A adoção de leguminosas em pastagens surge para suprir os níveis de nitrogênio que, ao longo dos anos, torna-se insuficiente para o desenvolvimento satisfatório das gramíneas. Logo, a consorciação em pastagens é uma forma de aumentar o aporte de $\mathrm{N}$ no sistema, uma maneira econômica, sem uso abusivo de fertilizante e compensatória para o produtor.

O N fixado biologicamente é introduzido na proteína da leguminosa, que é consumida pelo animal e atende seus requerimentos protéicos, e o excesso retorna ao sistema na forma de fezes. Alternativamente, o $\mathrm{N}$ retorna ao solo como matéria orgânica. As leguminosas fixam $\mathrm{N}$ e funcionam como fonte deste nutriente às gramíneas as quais estão associadas. Atualmente, segundo Paulino et al. (2000), a adoção desta tecnologia é recomendável, constituindose como uma alternativa ao uso do adubo nitrogenado, pois permite a sustentabilidade dos sistemas de produção a um custo mais baixo, e que oferece menores danos ao meio ambiente.

As leguminosas ainda são utilizadas como cobertura do solo, ou seja, como adubo verde, favorecendo para aumentar a matéria orgânica do solo, bem como ciclagem de nutrientes, pois tanto nitrogênio, como água e outros nutrientes são beneficiados com a camada em decomposição que se origina com a deposição de substratos provenientes das leguminosas.

Em olericulturas, as leguminosas são utilizadas com fins fertilizantes, pois sua decomposição e incorporação no solo beneficiam uma maior fertilidade dos canteiros onde são produzidas as culturas, bem como evitar prejuízos com chuvas intensas e falta de água no sistema (Paulino et al., 2000).

Já em pastagens, a fertilidade do solo, proveniente da introdução de leguminosas, é de acordo com a fixação biológica de nitrogênio, pois este é o principal nutriente que modula a produção de forrageiras, que, com a fixação, passa a desempenhar mais seu potencial e beneficiar a produção animal. 


\subsection{Melhorias na Produção Animal}

A principal expectativa do uso de leguminosas em pastagens é a melhoria da produção animal em relação à pastagem de gramínea exclusiva, com redução dos custos de produção, quando comparados com pastagens submetidas à adubação com nitrogênio mineral. Este benefício, conforme relatado por Pereira (2002), é reportado como sendo efeito da participação direta da leguminosa melhorando e diversificando a dieta do animal e também do aumento da disponibilidade de forragem pelo aporte de nitrogênio ao sistema, através da sua reciclagem e transferência para a gramínea acompanhante.

As leguminosas apresentam, geralmente, melhor valor alimentício em relação às gramíneas, com maiores níveis de proteína bruta $(P B)$ e de digestibilidade, refletindo em melhor desempenho animal em pastagens consorciadas (Pereira, 2002).

Inúmerostrabalhos indicam aumento no ganho ou manutençãodo peso de animais durante o período da seca, comoresultado da melhor qualidade da leguminosa emassociação com gramíneas (Tabela 3). Extensas revisõesno Brasil sobre leguminosas subsidiam a importância eo potencial de adoção das pastagens consorciadas comleguminosas (Andrade \&Karia, 2000; Barcellos et al,2001; Pereira, 2002).

A digestibilidade das leguminosas tropicais no pasto em oferta é maior que das gramíneas, mas observa-se diferença entre espécies ou cultivares. Dependendo do cultivar, de acordo com relatos de Pereira (2002), pode ocorre baixa disponibilidade, altos teores de tanino e outros fatores antiqualitativos têm contribuído para reduzir a palatabilidade e a preferência de leguminosas pelos animais, com possível adaptação prévia dos cultivares para serem consorciadas. 
Tabela 3 - Efeito de pastagens de Brachiariaspp recuperadas pela introdução de Stylosanthesguianensis cv. Mineirão, em dois solos de Uberlândia (MG), no ganho de peso de novilhas nelore.

\begin{tabular}{ccccc}
\hline Épocas/Local & g/dia/an. & UA/ha & g/dia/an. & UA/ha \\
\hline Faz. Cachoeira & B. ruziziensis + Minerão & B. ruziziensis pura \\
\hline Anual (kg/ha) & \multicolumn{2}{c}{303} & \multicolumn{2}{c}{190} \\
Chuvas & 450 & 1,42 & 406 & 1,27 \\
Seca & -12 & 0,86 & -72 & 1,18
\end{tabular}

Faz. Santa Inês ${ }^{3}$

\begin{tabular}{|c|c|c|c|c|}
\hline Anual (kg/ha) & \multicolumn{2}{|c|}{460} & \multicolumn{2}{|c|}{301} \\
\hline Chuvas & 622 & 1,51 & 511 & 1,17 \\
\hline Seca & 205 & 0,8 & 131 & 0,8 \\
\hline
\end{tabular}

Esses fatores podem ser analisados na Tabela 4, onde observa-se que pastagens consorciadas apresentaram maiores níveis de proteína bruta e digestibilidade, mesmo que in vitro, que comprovam as melhorias da qualidade de pastagens que são consorciadas com leguminosas.A consorciação de pastagens permite uma maior produtividade animal, já que ocorre um aumento na produção relativa em $\mathrm{kg} / \mathrm{ha} / \mathrm{ano}$ se comparado com pastagens em monocultivo (Pereira, 2002).

Segundo Barcellos et al. (2008), estudos desenvolvidos no norte da Austrália, em país com regiões de clima tropical e reconhecidamente adepto de leguminosas na alimentação de ruminantes, reportam resultados significativos quanto ao desempenho animal. Uma grande proporção das pastagens consorciada (60\%) gerou ganhos em pesoentre 400 e $800 \mathrm{~g} / \mathrm{animal} / \mathrm{dia}$. Esta resposta, quando aplicados à situação brasileira, possibilitaria aterminação de animais em regime exclusivo de pastocom idade inferior a 36 meses. Para a 
recria de fêmeas,tanto de gado de corte como leiteiro, seria possível a entrada dos animais em reprodução com idade entre 18 e 20 meses.

Tabela 4 - Teores de proteína bruta (PB) e digestibilidade in vitro da matéria seca (DIVMS) em algumas leguminosas sob pastejo.

\begin{tabular}{lcccc}
\hline \multirow{2}{*}{ Pastagem } & \multicolumn{2}{c}{ PB } & \multicolumn{2}{c}{ DIVMS } \\
\cline { 2 - 5 } & Gram. & Leg. & Gram. & Leg. \\
\hline B. humidicola & 6,1 & - & 41,4 & - \\
B. humidicola + D. ovalifolium & 6,9 & 9,1 & 40,0 & 35,3 \\
B. humidicola + P. phaseoloides & 7,7 & 12,5 & 45,3 & 45,1 \\
B. decumbens & 7,7 & - & - & - \\
B. decumbens + Calopogonio & 8,7 & 11,5 & 53,4 & 40,0 \\
B. brizantha & 4,0 & - & - & - \\
B. brizantha + Calopogonio & 7,4 & 11,5 & 39,2 & 40,0 \\
B. humidicola + A. pintoi & 6,1 & 18,6 & - & - \\
B. humidicola + S. guianensis & 6,1 & 15,6 & - & - \\
B. brizantha + L. leucocephala & 5,5 & 22,5 & 52,3 & 60,7 \\
\hline
\end{tabular}

Fonte: Adaptado de Pereira, 2002.

Esse ganho em peso dos animais é consequência do incremento na dieta, com maior quantidade de proteína devido a as características das leguminosas, que beneficia o alimento dos animais na época da seca, onde a qualidade das pastagens deixa a desejar e os animais acabam perdendo peso e não desempenham o potencial produtivo desejado.Em média, segundo dados compilados (Pereira, 2002) os pastos consorciados proporcionaram 437 g/animal/dia (variando de 230-610g/dia) e os pastos exclusivos $333 \mathrm{~g} / \mathrm{dia}$ (variação de 117-574 g/dia).As taxas de lotação foram bastante variáveis, desde 0,5 cabeça/ha até 2,4 UA/ha (UA=unidade animal= $450 \mathrm{~kg}$ de peso vivo). Em geral, os trabalhos recentes em sistemas extensivos nos locais com estação seca bem definida não têm proporcionado taxas de lotação acima de $1,5 \mathrm{UA} / \mathrm{ha}$ /ano. 
No Gráfico 4, podemos observar a diferença de ganho de peso em novilhas azebuadas em pastagens exclusivas e consorciadas de Andropogon gayanus com Stylosanthes guianensiscv. Mineirão durante os períodos de seca e chuvas. Já que uma das limitações do Andropogon é sua baixa qualidade na estação seca que pode ser superada com a associação gramínea e leguminosa (Barcellos et al., 2008).Isso nos proporciona avaliar que pastagens consorciadas possuem características que aumentam o ganho de peso, seja pelo incremento na dieta ou pela disponibilização de nutrientes provenientes da fixação biológica de nitrogênio, que aumenta a produção das gramíneas.

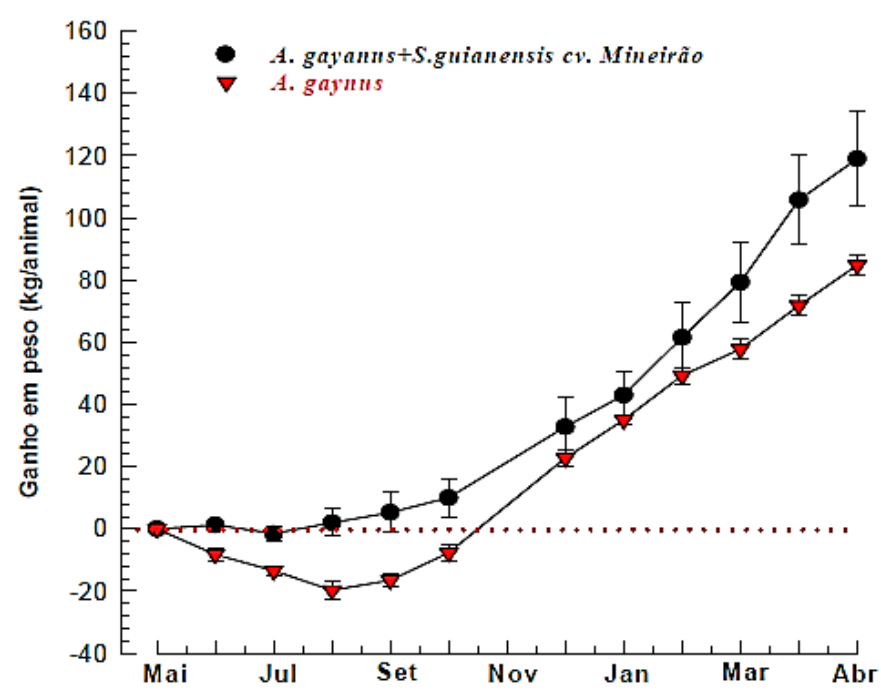

Gráfico 4 - Efeito de leguminosas no ganho de peso de novilhas azebuadas durante os períodos de seca e chuvas (1993/94). Fonte: Vilela et al. (2001).

Para a produção de leite, a utilização de $A$. pintoiem sistemas de produção tem gerado resultados expressivos (Tabela 5).Em pastagens de capim Estrela puro e consorciado foram obtidos aumentos na produção diária de leite entre 1,1 e 1,4 kg de leite/vaca. A produção por área foi aumentada em 14,3\% e 13,6\% em dois períodos de avaliação (Gonzales et al. 1996). Os autores relatam que as produções poderiam ser ainda maiores se fosse adotada a suplementação dos animais com uma fonte de energia para aumentar a eficiência do uso do excedente de nitrogênio ruminal. Esta 
observação tem grande relevância no manejo alimentar de animais consumindo $A$. pintoi, devido à alta taxa de degradação protéica dessa forragem, exigindo o uso de energia prontamente disponível para maximizar seu potencial nutritivo (Ladeira et al. 2002).

Tabela 5 - Produção de leite em pastagens de capim Estrela Africana (Cynodon nlemfuensis) em monocultivo e consorciado com Arachis pintoi.

\begin{tabular}{|c|c|c|c|}
\hline \multirow{2}{*}{ Produção } & Capim Estrela & Estrela + A. pintoi & Incremento (\%) \\
\hline & \multicolumn{2}{|r|}{1990} & \\
\hline $\mathrm{kg} / \mathrm{vaca} / \mathrm{dia}$ & $7,7 \mathrm{~b}$ & $8,8 a$ & \\
\hline \multirow[t]{2}{*}{ * kg/vaca/dia } & 22,3 & 25,5 & 14,3 \\
\hline & \multicolumn{2}{|c|}{ 1991-1992 } & \\
\hline $\mathrm{kg} / \mathrm{vaca} / \mathrm{dia}$ & $9,5 \mathrm{~b}$ & $10,9 \mathrm{a}$ & \\
\hline * kg/vaca/dia & 22,8 & 25,9 & 13,6 \\
\hline
\end{tabular}

* Lotação de 2,9 e 2,4 U.A. em 1990 e 1991/1992, respectivamente.

Fonte: Adaptado de Gonzalez et al. (1996).

A partir deste contexto, podemos concluir que o incremento na produção animal devido à consorciação de gramíneas e leguminosas é benéfico para a produção em pastagens. O ganho de peso e o aumento na produção de leite em pastagens com consórcio é evidente, pois a qualidade da dieta é melhorada devido à introdução de plantas com nível de proteína satisfatórios, que beneficiam o ganho de peso animal.

\subsection{Redução dos Custos de Produção}

Com a fixação biológica de nitrogênio, tanto o produtor como o meio ambiente passam a ser beneficiados, pois ocorre diminuição do uso de fertilizantes nitrogenados, com menor agressão ao recursos naturais, sem lixiviação do excesso de produtos, que contaminam o lençol freático e sem prejuízos para o próprio solo. 
Com relação ao produtor, a economia em insumos é significativa, considerando que a leguminosas fixará $100 \mathrm{~kg}$ de N/ha (Spain et al., 1990) e o produtor possuindo uma pastagem com área considerada grande, sem utilizar de recursos para manutenção ou adubação para aumentar a produção, o nitrogênio fixado é uma forma de contribuir para a qualidade da pastagem bem como atribuir recursos para a produção e diminuição de custos.

Observando essas considerações, conclusões positivas podem ser tomadas, pois em sistemas que não ocorre nenhuma manutenção e, às vezes, sem gerar importância pelo produtor, a introdução de leguminosas no sistema vem para beneficiar a produção da gramínea, disponibilizando $\mathrm{N}$ para seu desenvolvimento, sem grandes custos, apenas para adquirir as sementes de leguminosas, que não possuem valor acentuado.

Em relação à redução de custos, o preço é variável de acordo com o preço dos fertilizantes de cada região. Entretanto, nos sistemas intensivos de criação a pasto os gastos diretos com fertilizantes podem representar mais de $60 \%$ do custo de produção, implicando ainda custos agregados com transporte, armazenamento e aplicação, além de uma eficiente gestão da produção e utilização da forragem produzida (Barcellos et al., 2008)

O produtor ainda deve avaliar as condições que a pastagem se encontra, pois em altos níveis de degradação a leguminosa não consegue expressar seu máximo potencial, não auxiliando positivamente para o desempenho da gramínea, onde muitas vezes, podem competir por nutriente já escasso, sem contribuir para o sistema de produção.

\section{LIMITAÇÕES PARA O ESTABELECIMENTO DE LEGUMINOSAS}

Existem inúmeras diferenças entre gramíneas e leguminosas do ponto de vista produtivo, como questões de morfogênese, crescimento, tolerância ao pastejo, mecanismo para manutenção da população, dentre outros (Pereira, 2002). Spain \& Vilela (1990), reforçam, ainda, que a não persistência da leguminosa sempre foi atribuída à agressividade da gramínea, a não adaptação 
as pressões bióticas e abióticas, ao manejo imposto e não reposição de nutrientes exportados na forma de produto animal.

Segundo Pereira (2002) alguns fatores são inerentes as características que as leguminosas devem ter para persistir em associações com as gramíneas enquanto outros estão relacionados como um universo todo, uma amplitude de fatores que possam interferir.

\subsection{Germoplasma Adaptado}

A escolha da espécie para ser implantada em um sistema de consorciação é de suma importância para o bom desempenho da produção e resiliência de um consórcio, pois a adequação de características faz com que o desenvolvimento de ambas as plantas seja benéfico e não cause prejuízos ou insatisfação do produtor.

Milhares de acessos de leguminosas estão em banco de germoplasma e centenas já passaram pelas fases de avaliação de adaptabilidade e produção agronômica. No entanto, poucas são as que chegam à fase de avaliação sob pastejo, a qual deveria ser realizada já nos estágios iniciais envolvendo a gramínea (Pereira, 2002).

$\mathrm{Na}$ opinião de Barcellos et al. (2000), o desenvolvimento de novos cultivares deve estar atrelado ao sistema de produção do qual vão participar e este comportamento certamente reduziria os insucessos observados em muitas pesquisas de avaliação de leguminosas, contribuindo para sua maior adoção.

Dentro dessas opiniões, pode observar que a escolha do germoplasma deve ser bem analisada, pois as características das leguminosas não podem ser suprimidas pela gramínea, que possui crescimentos e hábitos mais agressivos. A compatibilidade das espécies deve ser atribuída ao sucesso do sistema e maior desempenho do consórcio, visto que, toda uma harmonia deve ser estabelecida.

As espécies escolhidas devem apresentar boa resistência ao pastejo, capacidade de rebrote, boa produção de sementes, ou seja, boa ressemeadura natural e, além disso, boa capacidade de competição, já que irá ocorrer 
disputa por água e nutrientes do solo, e que, ambas, possam ser beneficiadas e supridas (Pereira, 2002).

\subsection{Fatores Ecofisiológicos}

A persistência da leguminosa na consorciação com gramíneas, já seria de inicio considerada difícil por uma diferença fundamental: as leguminosas são do tipo C3 e as gramíneas do tipo C4. Dentre as diferenças fisiológicas, as plantas C4 são mais eficientes do ponto de vista fotossintético, o que thes confere maior taxa de crescimento.Em decorrência, as leguminosas levam grande desvantagem na competição com as gramíneas, para se manterem persistentes na área (Pereira, 2002).

Além da taxa de crescimento individual, na definição das espécies ou cultivares a serem consorciados, avalia-se também seu comportamento ao longo do ano, onde gramíneas e leguminosas isoladas possuem diferentes comportamentos, principalmente em função da competição por luz, água e nutrientes (Pereira, 2002).

Fatores morfogenéticos são também importantes para a persistência das forrageiras, pois são determinantes na capacidade de rebrotação após a desfolha. Segundo Pereira (2002), o meristema apical está localizado em locais diferentes em gramíneas e leguminosas, ocasionando maior ou menor eliminação pelo pastejo. Esse fator é importantíssimo para o estabelecimento de um sistema de consorciação, pois o manejo do pastejo deve ser muito bem manipulado para que não ocorra um colapso no sistema e a leguminosa inserida não consiga se adequar as condições.

Em contrapartida, Andrade (2010), assume que a incompatibilidade fisiológica não seria a maior razão para que gramíneas e leguminosas não pudessem sem consorciadas com grande satisfação, admitindo que a tolerância ao pastejo e persistência das leguminosas são fatores que mais evidenciam o insucesso de determinados consórcios. 
As diversas espécies de leguminosas possuem adaptações fisiológicas para determinado estresse adquirido, onde a ressemeadura natural, resistência ao pisoteio e pastejo, dentre outros, são característica que permitem analisar quais espécies possui atributos ecofisiológicos que possam resistir ao sistema de consorciação com grande eficiência e produtividade.Mesmo que as plantas possuam diferenças fisiológicas, a adaptação a consorciação pode ser adquirida com planejamento do sistema e implantação de espécies que favorecem o desempenho da pastagem em geral.

Espécies como A. pintoi, D. ovalifolium, N. wigtii, P. phaseoloidesdentre outras leguminosas, segundo Pereira (2002), possuem boas características para se adaptarem bem as condições de consórcio, onde principalmente o $A$. pintoipossui crescimento muito parecido com os das gramíneas, com estolões e decumbentes, com alta eficiência de mecanismos de autopropagação, aproveitando melhor a água, nutrientes e luz, favorecendo ainda mais sua adaptação em sistemas de consorciação.

\subsection{Fatores Agronômicos}

A formação de pastagens não possui a mesma atenção quando comparado aos sistemas agrícolas, associando as próprias adversidades do ambiente e ao manejo inadequado tem comprometido a sustentabilidade das pastagens. Porém, na formação de pastagens consorciadas, a situação se agrava ainda mais, seja pelo desconhecimento de técnicas ou precariedade no estabelecimento de culturas diferentes.

$\mathrm{Na}$ formação de pastagens consorciadas as técnicas de plantio geralmente visam dar melhor condição de estabelecimento a leguminosa em relação a gramínea, onde Zimmer et al., 1994, recomenda a redução da taxa de plantio da gramínea em 30 a 40\%, com adubação estratégica para a leguminosa.

Mesmo quando se pensa em consorciação atrelada a fixação de nitrogênio, o solo deve ser passar por técnicas de formação, para que ambas 
as espécies tenham condições para a germinação, observando as características de cada espécie e aptidão para determinados tipos de solo, visando uma formação uniforme das plantas e bom desempenho do sistema.

\section{POTENCIALIDADES E PERSPECTIVAS DO USO DE CONSÓRCIOS}

As perspectivas para as próximas décadas, com um cenário de mudanças climáticas globais, elevação dos preços do petróleo, mudanças na matriz energética, controle de gases do efeito estufa, dentre outros, justificam plenamente o investimento em pesquisas visando ampliar a produção de ruminantes em pastagens consorciadas de gramíneas e leguminosas. Essa tecnologia, segundo Andrade (2010) se encaixa perfeitamente dentro da filosofia de intensificação da produção pecuária de forma sustentável, tanto nas regiões tropicais quanto nos países de clima temperado.

Entretanto, de acordo com Silva (2008), na maior parte das vezes a intensificação da produção tem sido feita por meio de uso exagerado de corretivos, fertilizantes e irrigação, sem se levar em consideração aspectos importantes relacionados com as respostas de plantas forrageiras e animais em ambientes de pastagens e melhorias correspondentes, necessárias, no processo de colheita eficiente da forragem produzida e preservação ambiental. O resultado tem sido uma distorção do conceito de intensificação e impactos ambientais negativos, relacionados com adensamento do solo, erosão, eutrofização e os riscos a ela associados.

O uso da técnica de consorciação, a primeira vista, causa certa frustação e preocupação de técnicos e produtores, devido as características das gramíneas que resultam na redução do estande de leguminosas e o consórcio acaba em insucesso.

E então, o problema não tem solução? Não é possível utilizar leguminosas em pastos tropicais de maneira associada com as gramíneas? A resposta a essas questões, segundo Silva (2008) requer reflexão e reavaliação 
de alguns conceitos e premissas básicas que regem a produção animal em pasto.

É preciso revisar conceitos e mudar paradigmas relativos às plantas forrageiras tropicais, gramíneas e leguminosas, e reconhecer que o grande desafio da pesquisa e do desenvolvimento tecnológico nessa área do conhecimento virá de progressos no entendimento e compreensão de aspectos do processo de crescimento e desenvolvimento de comunidades mistas de plantas forrageiras (Silva, 2008).

Apesar das relevantes possibilidades de contribuição para produção a pasto e dos muitos esforços por diferentes instituições de ensino e pesquisa, o uso de leguminosas em pastagens no Brasil ainda é muito limitado. Isso, segundo Barcellos et al. (2008), pode ser devido ao portfólio de cultivares ser pequeno, o preço da semente ou do material vegetativo é elevado, a persistência sob pastejo é limitada, o estabelecimento é lento ou, principalmente, porque 0 real papel que elas podem desempenhar nos sistemas de produção de bovinos é desconhecido.

Para a reversão desse quadro, pastagens consorciadas devem gerar a percepção de tecnologia de baixo risco e de baixo custo. Para tanto, a adoção deve ser fundamentada no conhecimento das potencialidades e limitações dos cultivares e na detecção das melhores oportunidades de inclusão nos sistemas de produção de bovinos, visando ampliar o uso dessa opção tecnológica (Barcellos et al. 2008).

\section{CONCLUSÃO}

No Brasil, pastagens consorciadas de gramíneas e leguminosas já são realidades em diversas regiões e deverão conquistar, a cada ano, maior grau de importância. A técnica e o conhecimento dos processos estão evoluindo bastante, porém, ainda há necessidade de esforços para aumentar o número de pesquisas com a utilização de culturas mistas. 
SIMIONI, T.A. et al. Potencialidade da consorciação de gramíneas e leguminosas forrageiras em pastagens tropicais. PUBVET, Londrina, V. 8, N. 13, Ed. 262, Art. 1742, Julho, 2014.

É necessário o conhecimento das espécies desejadas para implantação de um consórcio, possuindo as características favoráveis para adaptação da consorciação. Esse tipo de pesquisa é um grande desafio e talvez seja imprescindível buscar outros parâmetros de avaliação, tendo em vista que a funcionalidade do sistema é mais importante que o tipo de planta especificamente, seja gramínea ou leguminosa.

\section{REFERÊNCIAS BIBLIOGRÁFICAS}

ALLOS, H.F.; BARTHOLOMEW, W.V. Replacement of symbiotic fixation with available N. Soil Sci., v.87, pag.61-67, 1959.

ANDRADE, C. M. S. Produção de Ruminantes em Pastos Consorciados. In: V Simpósio sobre Manejo Estratégico da Pastagem. Viçosa, MG, UFV: DZO, 2010.

ANDRADE, R. P; KARIA, C. T. Uso de Stylosanthes em pastagens no Brasil. In: Simpósio de Forragicultura e Pastagens: Temas em Evidência, Lavras. Anais, 2000.

ASSMANN, A. L et al. Produção de gado de corte e acúmulo de MS em sistema de integração lavoura pecuária em presença e ausência de trevo branco e nitrogênio. Revista Brasileira de Zootecnia, Viçosa, p. 37-44, 2004.

BRISKE, D. D. Strategies of plant survival in grazed systems: a functional interpretation. CAB International, p. 37-67, 1996.

BARCELLOS, A.O.; ANDRADE, R.P.; KARIA, C.T.; VILELA, L. Potencial e uso de leguminosas forrageiras dos gêneros Stylosanthes, Arachis e Leucaena. Simpósio sobre Manejo da Pastagem, Piracicaba. Anais... Piracicaba: FEALQ, p.365-426, 2001.

BARCELLOS, A. O; RAMOS, A. K. B; VILELA, L. MARTHA JUNIOR, G. B. Sustentabilidade da produção animal baseada em pastagens consorciadas e no emprego de leguminosas exclusivas, na forma de banco de proteína, nos trópicos brasileiros. Revista Brasileira de Zootecnia, v.37, p.51-67, 2008.

CADISCH, G.; SCHUNKE, R.M.; GILLER, K.E. Nitrogen cycling in a pure grass pasture and a grass-legume mixture on a red latosol in Brazil .Trop. Grassl.,v.28, n.1, pag. 43-52, 1994.

CALEGARI, A.; MONDARDO, A.; BULISANI, E.A.; WILDNER, L.P.; COSTA M.B.B.; ALCANTARA, P.B.; MIYASAKA, S. \& AMADO, T.J.C. Adubação verde no Brasil. 2.ed. Rio de Janeiro, ASPTA, 1993. 346p.

CANTARUTTI, R.B; BODDEY, R.M. Transferência de nitrogênio das leguminosas para as gramíneas. In: Simpósio Internacional Sobre Produção Animal Em Pastejo, Viçosa, MG, 1997. Anais... Viçosa: UFV, pag. 431-445, 1997.

CARVALHO, M. A. Caracterização dos componentes agronômicos da produção de forragem e sementes de Arachispintoi e Arachisrepens (LEGUMINOSAE). Dissertação de Mestrado, Departamento de Engenharia Agronômica, Universidade de Brasília, Brasília, DF, 117 p. 1996.

CARVALHO, M.M. Fixação biológica como fonte de nitrogênio em pastagens. In: SIMPÓSIO SOBRE CALAGEM E ADUBAÇÃO DE PASTAGENS. Nova Odessa, SP, 1985. Anais... Piracicaba: POTAFÓS, pag.125-143, 1986. 
CONN, E.E.; STUMPF, P.K. Introdução à bioquímica. 3. ed. São Paulo: Edgard Blücher, 1975. $447 \mathrm{p}$.

DÖBEREINER, J. Biological Nitrogen Fixation in the Tropics: Social end Economic

Contributions. Soil Biol. Biochem., pag.771-774, 1997.

FERGUSON, J. E.; CARDOSO, C. I.; SÁNCHEZ, M. S. Avances y perspectivas enlaproducción de semilla de Arachispintoi. PasturasTropicales, v. 14, n. 2, p. 14-22, 1992.

FERNÁNDEZ, A.; KRAPOVICKAS, A. Cromosomas y evolución em Arachis (Leguminosae). Bonplandia, v.8, p.187-220. 1994.

FERREIRA, M. B.; COSTA, N. M. S. O gênero StylosanthesSw. no Brasil. Belo Horizonte, MG, Epamig, pag. 108, 1978.

FREITAS, A.R.D.; OLIVEIRA, A.L.P.C.D.; SILVA, B.A. da; DECICO, M.J.U. LeucaenaleucocephalaLam. (De Witt): cultura e melhoramento. EMBRAPA-UEPAE São Carlos. Documentos, 12. 1991.

GEBHART, D.L.; CHRISTOPHER, A.C.; WEAVER, R.W. Dinitrogen fixation and transfer in legume-crested whetgrassmistures. J. Range Manage., v.46, pag.431-435, 1993.

GALLO. L. A; BASSO, L. C. O Nitrogênio e o Ciclo do Nitrogênio. Escola Superior De Agricultura Luiz De Queiroz - Esalq, Depto. Ciências Biológicas, 2012.

GONZALES, M. S.; NEURKVAN, L. M.; ROMERO, F. et al. Producion de lecheenpasturas de estrella africana (Cynodonnlemfluensis) solo y associado conArachispintoi 0 Desmodiumovalifolium. Pasturastropicales, v. 18, n. 1, p. 2-12. 1996.

HANDARSON, G. Methods for enhancing symbiotic nitrogen fixation. Plant Soil, 152:1-17, 1993.

HOWIESON, J. G.; YATES, R. J.; FOSTER, K. et al. Prospects for the future use of legumes. Nitrogen-fixing Leguminoses Symbioses, p. 363-393, 2008.

HUMPHREYS, L.R. Tropical forages: their hole in sustainable agriculture. Esses, UK: LongmanScientific\&Technical, pag. 414, 1994.

INSTITUTO BRASILEIRO DE GEOGRAFIA E ESTATÍESTICA - IBGE. [2010]. Pesquisa Agrícola Municipal, 2010. v.38, 61p. Disponível em: < www.ibge.gov.br /home/estatistica/economia/ppm/2010/ppm2010.pdf> Acesso em: 22 de maio de 2013.

KERRIDGE, P. C. Future prospects for utilization and research in forage Arachis. In: KERRIDGE, P. C.; HARDY, B. (eds.). Biology and Agronomy of Forage Arachis.Cali, Colômbia: CIAT, Capitulo 17. p. 199-206, 1994.

KRAPOVICKAS, A.; GREGORY, W. C. Taxonomia del género Arachis (Leguminosae). Bonplandia, Corrientes, v. 8, p. 1-186, 1994.

LAL, R, Tillage and agricultural sustainability.SoilTillage Res. pag. 133-146, 1991.

LADEIRA, M. M.; RODRIGUEZ, N. M.; BORGES, I.; GONÇALVES, L. C. ; SALIBA, E. O.S.; BRITO, S. C.; SÁ, L. A. P. Avaliação do Feno de Arachispintoi Utilizando o Ensaio de Digestibilidade in Vivo . Revista Brasileira de Zootecnia, v.31, n.6, p.2350-2356, 2002.

MAPA - Ministério da Agricultura, Pecuária e Abastecimento. Projeções do Agronegócio: Brasil 2011/2012 a 2021/2022. Brasília: Mapa/ACS, 76 p. 2012.

MENGEL, K., KIRKBY, E.A. Principles of plant nutrition. Bern: International Potash Institute, 1987. 687p.

MILLER, D.A.; HEICHEL, G.H. Nutrient metabolism and nitrogen fixation.Iowa StateUniversity Press, Ames, Iowa, pag.45-53, 1995. 
MIRANDA, C. H. B.; VIEIRA, A.; CADISCH, G. Determinação da fixação biologia de nitrogênio no amendoim forrageiro (Arachis spp.) por intermédio da abundancia natural de N. Revista Brasileira de Zootecnia, v. 32, p. 1859-1965, 2003.

MONTEIRO, H. C. F. Transferência de Nitrogênio de Leguminosas para Gramíneas. Viçosa, MG, 1998.

MOREIRA, F. M. S,; SIQUEIRA, J. O. Microbiologia e Bioquímica do Solo. Lavras, UFLA, pag. 625, 2002.

NASCIMENTO Jr., D.; GARCEZ NETO, A. F.; BARBOSA, R.A.; ANDRADE, C. M. S. Fundamentos para o Manejo de Pastagens: Evolução e Atualidade. In:, Simpósio Sobre Manejo Estratégico da Pastagem, UFV, Viçosa, pag.149-196, 2002.

PAULINO, V. T.; LUCENA, M, A. C.; GERDES, L.; COLOZZA, M. T.; Sustentabilidade de Pastagens Consorciadas - Ênfase em Leguminosas Forrageiras. In: II Encontro Sobre Leguminosas. Embrapa. Cerrados, 2000.

PÊSSOA, C.; NOGUEIRA, M. Rally da Pecuária, 2012. In: http://www.rallydapecuaria.com.br/. Acesso em: junho de 2013.

PEIXOTO, A. M,; PEDREIRA, C. G. S.; MOURA, J. C.; FARIA, V. P. A Planta forrageira no sistema de produção. In: 170 Simpósio sobre Manejo da Pastagem. Anais...FEALQ, Piracicaba, 2001.

PEOPLES, M.B.; HERRIDGE, D.F. \& LADHA, J.K. Biological nitrogen fixation: An efficient source of nitrogen for sustainable agricultural production? PlantSoil, 174:3-18, 1995.

PEREIRA, J.M. Leguminosas Forrageiras em Sistemas de Produção de Ruminantes: Onde Estamos? Para Onde Vamos? In: Simpósio Sobre Manejo Pastagens, Viçosa, MG. Anais... UFV, pag. 109, 2002.

PEREZ, S.C.J.G.A.; FANTI, S.C. Crescimento e resistência à seca de leucena em solo de cerrado. Pesquisa Agropecuária Brasileira, Brasília, v.34, n.6, p.933-944, 1999.

RAVEN, P. H.; EVERT, R. F.; EICHHORN, S. E. Biologia Vegetal. Rio de Janeiro, Guanabara Koogan, pag. 728, 1996.

SANTOS, H. P.; FONTANELI, R. S. BAIER, A. C.; Principais forrageiras para integração lavoura pecuária, sob plantio direto, nas regiões de Planalto e Missões do Rio Grande do Sul. Embrapa Trigo, 142 p. 2002.

SCHIFINO-WITTMANN, M. T. Citogenética do gênero LeucaenaBenth. Ciência Rural, Santa Maria, v.34, n.1, p.309-314, 2004.

SILVA, M. P. \& ZIMMER, A. H. Avaliação agronômica de consorciações de braquiárias e Andropogongayanus com novos acessos de estilosantes sob pastejo. Reunião Anual da Sociedade Brasileira de Zootecnia. Campo Grande, MS. 2004.

SILVA, S.C. Desafios e Perspectivas para a Pesquisa e Uso de Leguminosas em Pastagens Tropicais: uma reflexão. In: II Encontro sobre Leguminosas.EMBRAPA Cerrados, 2008.

SPAIN, J. M.; VILELA, L. Perspectiva para Pastagem Consorciada na América Latina no anos 90 e Futuros. In: Reunião Da Sociedade Brasileira De Zootecnia. Anais...Campinas, SBZ, 1990.

STREIT, N. M; CANTERLE, L. P; CANTO, M. W; HECKTHEUER, L. H. As Clorofilas. Ciência Rural, Santa Maria, v.35, n.3, p.748-755, 2005.

SWIFT, M.J.; WOOMER, P. Organic matter and the sustainability of agricultural systems: definition and measurement. Chichester, UK: IITA/K.U. Leuven, pag. 3 - 18, 1993.

TAIZ, L. \& ZEIGER, E. Plant Physiology. Redwood City, California. The Benjamin/CummiingsPublising Company, pag.559, 2006. 
THOMAS, R.J. The role of the legume in the nitrogen cycle of productive and sustainable pastures. Grass For. Sci., v. 47, pag. 133-142, 1993.

TONIN, G. S. Influência da fonte de nitrogênio na atividade de enzimas envolvidas no processo de assimilação de amidas e ureídeos em cotilédones imaturos de soja mantidos em cultura. Tese de Doutorado em Fisiologia Vegetal. Campinas, SP: Universidade Estadual de Campinas, 1988.

VALLE, L. C. S.; SILVA, J. M.; SCHUNKE, R. M. Ganho de peso de bovinos em pastagens de Brachiaria decumbens pura e consorciada com Stylosanthes spp. cv. Campo Grande. In: Reunião Anual Da Sociedade Brasileira De Zootecnia, Piracicaba. Anais... Piracicaba: FEALQ, p. 175-176, 2001.

VALLS, J. F. M.; SIMPSON, C.E. Taxonomy, natural distribution, and attributes of Arachis.In P. C. KERRIDGE e B. HARDY, eds., Biology and Agronomy of Forage Arachis, Cali: Centro Internacional de Agricultura Tropical (CIAT), Chapter 1. p. 1-18, 1994.

VALLIS, I. Nitrogen relationships in grass/legume mixtures.CSIRO, Melbourne, Australia, pag.190-201, 1978.

VAN RAIJ, B. Fertilidade do solo e adubação. Piracicaba: Associação brasileira parapesquisa da potassa e do fosfato, 343p., 1991.

VILELA, L.; MIRANDA, J.C.L.; AYARZA, M.A.; SHARMA, R.D. Integração lavoura pecuária: atividades desenvolvidas pela Embrapa Cerrados. Planaltina: Embrapa Cerrados, 29p. 1999.

WENER, D.; NEWTON, W. E. Nitrofen fixation in agriculture, floresty and the environmente.Dordrecht, p. 347, 2005.

WHITEHEAD, D.C. The role of nitrogen in grassland productivity. Commonwealth Agric. Bureaux Bull., Hurley, Berkshire, UK., pag.48, 1970.

ZIMMER, A. H.; MACEDO, M. C. M.; BARCELLOS, A. O. Estabelecimento e Recuperação de Pastagens de Bachiaria. In: Simpósio Sobre Manejo De Pastagem. Piracicaba. Anais... FEALQ, 1994. 